\title{
Heat pump system built into the room with the implementation of air exchange and microclimate
}

\author{
Sergey Fedosov ${ }^{*}$, Vadim Fedoseev ${ }^{2}$, Nikolay Elin ${ }^{3}$, Vladimir Voronov ${ }^{2}$, and Svetlana \\ Loginova $^{2}$ \\ ${ }^{1}$ National Research Moscow State University of Civil Engineering, 129337, Moscow, Russia, \\ ${ }^{2}$ Ivanovo State Polytechnical University, 153000, Ivanovo, Russia \\ ${ }^{3}$ LLC "Energy-21 century", 153002, Ivanovo, Russia
}

\begin{abstract}
The efficiency and performance of an air heat pump system built into a room, together with supply and exhaust ventilation, currently requires a high-quality microclimate and clean air in the room. The transition in mass housing construction to the sealed windows with doubleglazed windows, along with the positive factors such as a decrease in heat loss and a decrease in noise in rooms, led to a deterioration in the air regime in a room with traditional natural ventilation systems. In the winter period of space heating, energy is spent, among other things, on heating the incoming cold air, and in quite significant quantities. At the same time, the required level of air exchange is necessary in both poorly and wellinsulated buildings. From this it follows that the heat consumption for ventilation without the use of special innovative engineering and technical solutions will not decrease from this, and the more insulated the building is, the higher in relative terms the ventilation costs will be. As a method for assessing the microclimate comfort, the authors propose the calculations and comparison of individual parameters of the thermal and humidity air regime for the room in accordance with the SanPiN standards. The supply and exhaust ventilation system with a heat exchanger (recuperation) has a number of advantages, which include: saving heat energy spent on heating the ventilation air, depending on the type of heat exchanger system; the efficiency level of air-thermal comfort in the room, due to the aerodynamic stability of the heat pump heating system and balanced heat exchange of the supply and exhaust air; the ability to maintain a minimum relative humidity in the supply and exhaust ventilation system in the range from 40 to $60 \%$, in which viruses are the least viable. The recovered warm air is not just thrown out of the building, but enters a specially equipped mixing chamber with intensively uniform mixing, which allows achieving the efficiency factor of the heat pump COP $=3.5$ and the ability to operate such an air heat pump system in climatic zones with the temperatures up to $-25^{\circ} \mathrm{C}$.
\end{abstract}

\footnotetext{
*Corresponding author: fedosov-academic@mail.ru
} 


\section{Introduction}

The applied energy-saving measures require the creation of a high-quality microclimate and air purity in the premises area, which entails additional consumption of energy consumption.

In the conditions of creating a microclimate in the premises, the problem of ecotechnological heat generation of individual houses and low-rise buildings on the basis of cost-effective air heat pump systems is extremely urgent.

To increase the efficiency and productivity of the air heat pump system built into the room, the authors use modern technological solutions - a mixing chamber and a recuperator installed in the boiler room of the building [1]. The use of supply and exhaust ventilation in the recuperation system together with the existing heat generation makes it possible to ensure the thermal and humidity conditions of the room not lower than the set values. Structurally, the supply and exhaust ventilation, located in a low-rise building, is directed by an air duct to the evaporator of the air heat pump on the one hand, and on the other, it provides the room through the air ducts with heated outside air (Fig. 1).

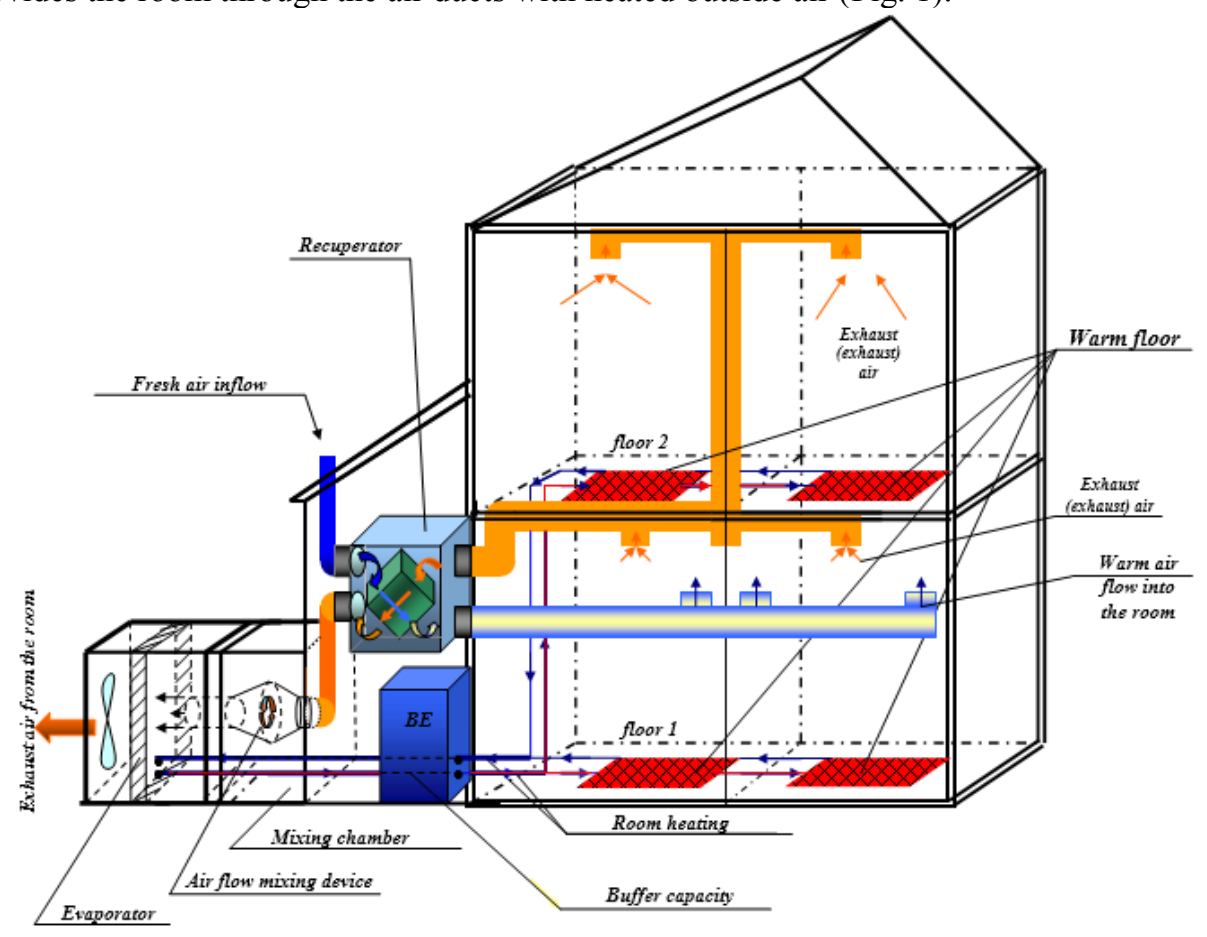

Fig. 1. Combined heat pump heating system

The necessary air exchange of the room, taking into account the air heat pump thermal power generation, to cover the heat losses and the creation of an efficient and rational operating mode, should be oriented towards the heat efficiency coefficient in the range $C O P=2.5 \div 4$, with the outside temperature as the closest to the climatic conditions in the Upper Volga regions [2].

It is proved in work [3] that the ambient air low-temperature heat transfer to the HHP inlet will be most effective at a temperature in the range of $8-12{ }^{\circ} \mathrm{C}$.

It should be noted that we achieve the supply of air mass (on average $t=10^{\circ} \mathrm{C}$ ) to the evaporator of an air heat pump due to a complex combination of an air-heating unit with a mixing chamber and a supply and exhaust ventilation system with recuperation, while 
maintaining the thermophysical properties (parameters) of the air the state of the environment in the room.

To ensure good air quality and its sanitary and biological efficiency, it is necessary to maintain a minimum relative humidity of the environment in the range from 40 to $60 \%$ [4].

\section{Methods}

The calculation of the thermal and humid regime with the thermophysical properties of humid air and the dependence of the relative air humidity on the temperature at the inflow in the recuperator was carried out according to the method [6-10]. Graphically, this dependence is shown in Fig. 2.

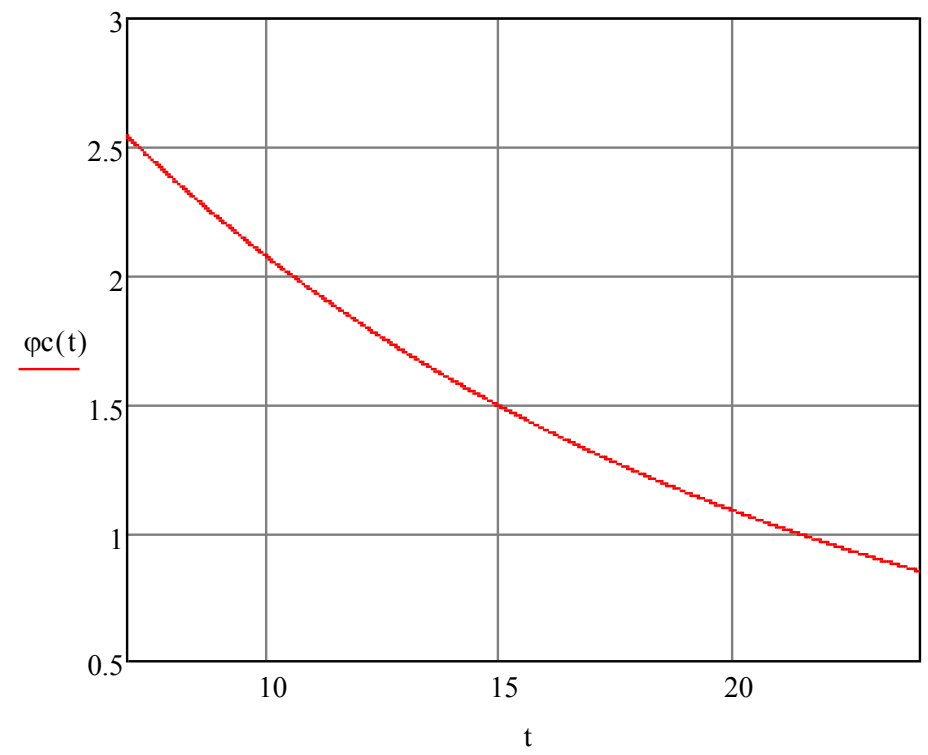

Fig. 2. Dependence of the relative air humidity on the temperature at the supply air in the room

Maximum possible amount of moisture in the form of water vapor $D_{m}$ :

$$
D_{m}(t)=0.622 \frac{P_{S}(t)}{P_{f}-P_{S}(t)},
$$

where: $P_{S}$ denotes saturation pressure, ata; $P_{f}$ shows working medium pressure, ata.

The amount of condensate $D_{k}$ is determined by the formula:

$$
D_{k}=D_{c}-D_{m}(t)
$$

where: $D_{c}$ is moisture content of the air at the critical point, $\mathrm{kg} / \mathrm{kg}$ dry. air;

$D_{m}$ is maximum possible amount of moisture, $\mathrm{kg} / \mathrm{kg}$ dry. air.

Then $D_{k}(t)=0.016-0.006=0.01 \mathrm{~kg} / \mathrm{kg}$ dry. air. 
Graphically, the dependence of the condensate $D_{k}$ amount on the room $t$ temperature is shown in Fig. 3.

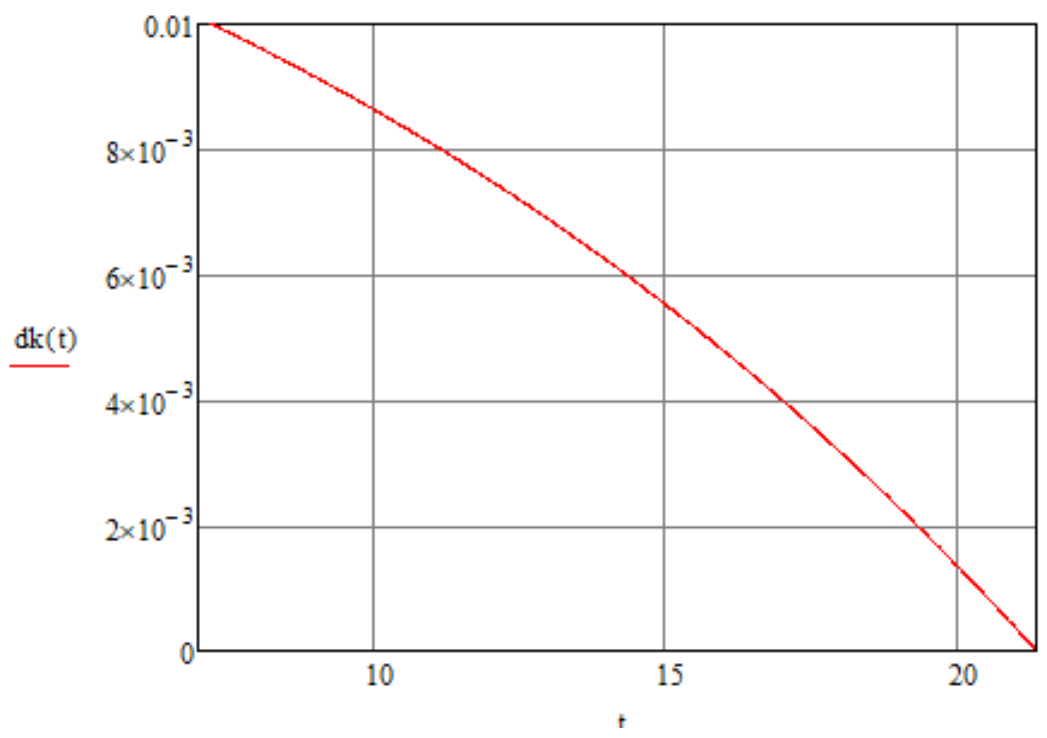

Fig. 3. Dependence of the condensate amount on the air temperature $t$ in the room

As a result of an approximate calculation, the dependence of the relative humidity and the amount of air condensate on the room temperature is obtained.

As an example, the calculation of the air flows state parameters in the air exchange system of a given room will be given.

As an example, let us give the calculation of the parameters in the room ${ }^{*}$ of air flows in the air exchange system of a given room at an outside air temperature that is economically beneficial for heat generation of air heat pumps up to $-10^{\circ} \mathrm{C}[11]$ and relative humidity in a heated room $-40 \% \div 50 \%$.

\section{Results}

Let us analyze the result of the two streams air exchange process: supply (outside) and exhaust (inside). The air flow parameters are presented in Table 1.

Table 1. Air flow parameters

\begin{tabular}{|l|c|c|c|}
\hline \multicolumn{1}{|c|}{ Airflow } & Temperature, $(t),{ }^{\circ} \mathrm{C}$ & $\begin{array}{c}\text { Relative humidi- } \\
\text { ty, }\left(\varphi_{k}\right), \%\end{array}$ & Consumption, $(G), \mathrm{m}^{3} / \mathrm{h}$ \\
\hline $\begin{array}{l}\text { Heating (from } \\
\text { the room) }\end{array}$ & 24 & 35 & 5 \\
\hline $\begin{array}{l}\text { Heated from the } \\
\text { street through } \\
\text { the supply duct }\end{array}$ & 7 & 65 & 8 \\
\hline
\end{tabular}

The calculation algorithm is shown in Fig. 4.

${ }^{*}$ We do not take into account the mixing chamber in the calculation, focusing only on the supply and exhaust flow 

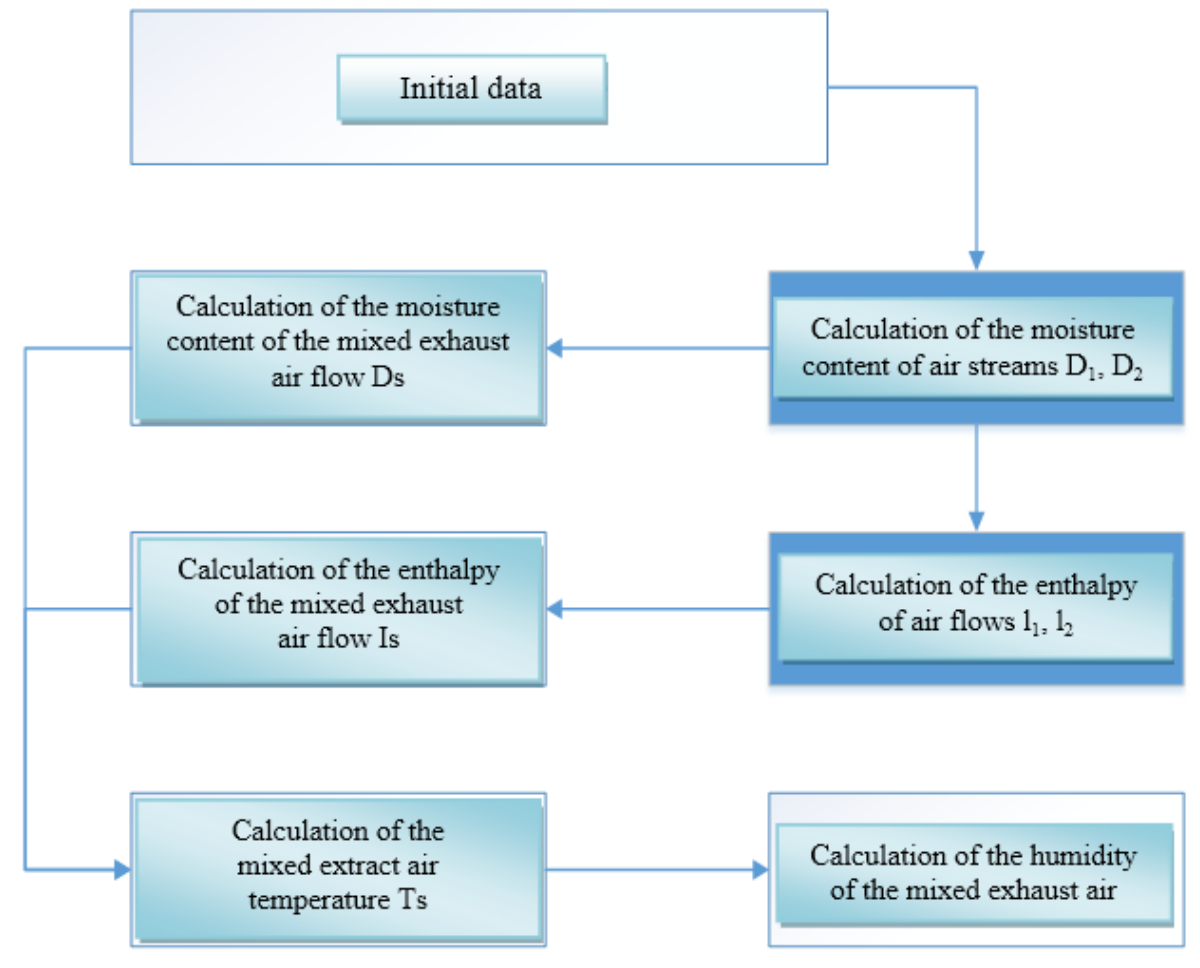

Fig. 4. Algorithm for calculating the supply and exhaust air environment parameters

The moisture content is calculated using the formula:

$$
D=0.622 \frac{\varphi \cdot P_{S}}{P-\varphi \cdot P_{S}}, \mathrm{~kg} / \mathrm{kg} \text { dry. air }
$$

where: $P_{f}$ is wet air pressure, $P_{S}$ defines saturation pressure, determined from the tables according to the humid air temperature $t$.

$$
\begin{aligned}
& D_{1}=\frac{0.622 \cdot 0.03 \cdot 0.35}{1-0.03 \cdot 0.35}=6.602 \cdot 10^{-3} \quad \mathrm{~kg} / \mathrm{kg} \text { dry. air } \\
& D_{2}=\frac{0.622 \cdot 0.01 \cdot 0.65}{1-0.01 \cdot 0.65}=4.069 \cdot 10^{-3} \quad \mathrm{~kg} / \mathrm{kg} \text { dry. air }
\end{aligned}
$$

Then the moisture content of the resulting air mixture will be equal to:

$$
D_{S}=\frac{D_{1} \cdot G_{1}+D_{2} \cdot G_{2}}{G_{1}+G_{2}}, \mathrm{~kg} / \mathrm{kg} \text { dry. air }
$$

where: $D_{1}, D_{2}$ define moisture content of air streams, kg / kg dry. air; $G_{1}, G_{2}$ show the consumption, $\mathrm{m}^{3} / \mathrm{h}$.

$$
\text { Then } D_{S}=\frac{6.602 \cdot 10^{-3} \cdot 5+4.069 \cdot 10^{-3} \cdot 8}{5+8}=5.043 \cdot 10^{-3} \mathrm{~kg} / \mathrm{kg} \text { dry. air. }
$$


The enthalpy of air flows is calculated by the formula [6]:

$$
I=t \cdot(D+1.93)+2501 \cdot D, \mathrm{~kJ} / \mathrm{kg}
$$

where: $t$ is air flow temperature, ${ }^{\circ} \mathrm{C} ; D$ is moisture content of the air flow, $\mathrm{kg} / \mathrm{kg}$ dry. air. Then:

$$
\begin{gathered}
I_{1}=t \cdot\left(D_{1}+1.93\right)+2501 \cdot D_{1}, \mathrm{~kJ} / \mathrm{kg} \\
I_{1}=24 \cdot\left(6.602 \cdot 10^{-3}+1.93\right)+2501 \cdot 6.602 \cdot 10^{-3}=46.479+16.512=62.991 \mathrm{~kJ} / \mathrm{kg} \\
I_{2}=t \cdot\left(D_{2}+1.93\right)+2501 \cdot D_{2}, \mathrm{~kJ} / \mathrm{kg} \\
I_{2}=7 \cdot\left(4.069 \cdot 10^{-3}+1.93\right)+2501 \cdot 4.069 \cdot 10^{-3}=13.539+10.177=23.716 \mathrm{~kJ} / \mathrm{kg}
\end{gathered}
$$

The specific enthalpy of the mixture is calculated by the formula:

$$
I_{S}=\frac{I_{1} G_{1}+I_{2} G_{2}}{G_{1}+G_{2}}, \mathrm{~kJ} / \mathrm{kg}
$$

where: $I_{1}, I_{2}$ show the specific enthalpy of air flows, $\mathrm{kJ} / \mathrm{kg} ; G_{1}, G_{2}$ denote the consumption, $\mathrm{m}^{3}$.

$$
I_{S}=\frac{62.991 \cdot 5+23.716 \cdot 8}{5+8}=38.82 \mathrm{~kJ} / \mathrm{kg}
$$

Air exchange (mixing) flow temperature: $T_{S}=\frac{I_{S}-2501 \cdot D_{S}}{D_{S}+1,93}, \mathrm{C}$

$$
T_{S}=\frac{I_{S}-2501 \cdot D_{S}}{D_{S}+1,93}, C
$$

where: $I_{S}$ is enthalpy of the air mixture, $\mathrm{kJ} / \mathrm{kg} ; D_{S}$ is moisture content of the air mixture, $\mathrm{kg} / \mathrm{kg}$ dry. air.

As a result, we get: $T_{S}=\frac{38.82-2501 \cdot 5.043 \cdot 10^{-3}}{5.043 \cdot 10^{-3}+1,93}=\frac{26,2075}{1,9354}=13,541,{ }^{\circ} \mathrm{C}$

Relative humidity of air exchange flows:

$$
\varphi_{S}=\frac{P_{f} \cdot D_{S}}{P_{S}\left(T_{S}\right) \cdot\left(D_{S}+0.622\right)}
$$

where: $D_{S}$ is moisture content of the air mixture, $\mathrm{kg} / \mathrm{kg}$ dry. air; $P_{S}$ is saturation pressure, ata; $P_{f}$ is working medium pressure, ata. 
Then $\varphi_{S}=\frac{1 \cdot\left(5.025 \cdot 10^{-3}\right)}{0.016 \cdot\left(5.025 \cdot 10^{-3}+0.622\right)}=0.501=50.1 \%$.

As a result of the calculations, we obtain the parameters of the supply and exhaust environment state in the room with an access to the air-heat pump and outside [7-9]. The calculation algorithm is shown in Fig. 4.

\section{Discussion}

The proposed combined heat supply system ensures the heat and humidity air environment state in accordance with the relevant GOST and SanPiN, regulating the minimum relative humidity in the room in the range of $40 \% \div 60 \%$ [12].

\section{Conclusion}

The proposed calculation of air exchange taking into account the heat pump and the obtained parameters of the room microclimate (structure) with an area of $100 \mathrm{~m}^{2}$, showed a reasonable energy-saving heat generation corresponding to an efficiency coefficient of COP $=2.5 \div 4[13-15]$.

The results of the study are useful for unifying the calculations of the obtained air heat fluxes, which, observing the calculated temperature and enthalpy, ensure the humidity and temperature conditions constancy in the room [15-19].

Air humidification systems should be included in each project of the climatic equipment of a building for any purpose to ensure its epidemiological safety.

\section{References}

1. V.A. Emelin, V.A. Voronov, I.A. Sviridov, RF patent No. 185689. Means for mixing gas streams / V.N. Fedoseev, A.B. Petrukhin, declared on 24.01. 2018, Publ. 12/13/2018. Bul. № 35 .

2. S.V. Filippov, M.S. Ionov, M.D. Dilman, Prospects for the use of air heat pumps for heating residential buildings in various climatic conditions, Heat power engineering 11, 11-18 (2012)

3. R.M. Aloyan, A.B. Petrukhin, N.V. Vinogradov, V.N. Fedoseev, Functional system for heat exchange of autonomous textile production with an air heat pump (VTH), Textile Industry Technology 5, 195-198 (2016).

4. S.V. Fedosov, V.N. Fedoseev, I.A. Zaitseva, Yu.E. Ostryakova, V.A. Emelin, V.E. Shebashev, Feasibility study for the use of energy efficient heat pump compressor devices in textile buildings, Bulletin of the Volga State Technological University. Series: Materials. Constructions. Technology 4(12), 111-119 (2019).

5. V.P. Isachenko, V.A. Osipova, A.S. Sukomel, Heat transfer (Energiya, Moscow, 1975)

6. V.A. Kirillin, V.V. Sychev, A.E. Sheindlin, Technical thermodynamics (Nauka, Moscow, 1969)

7. V.A. Voronov, V.A. Emelin, V.N. Fedoseev, I.A. Zaitseva, Climatic conditions and factors affecting the performance of an air heat pump, Theory and practice of technical, organizational, technological and economic solutions. Collection of scientific papers, 241-251 (2015). 
8. S.V. Fedosov, V.N. Fedoseev, I.A. Zaitseva, V.A. Emelin, High-tech and logical air heat pump system "three in one" for low-rise and cottage buildings, INSTRUMENTS 2(236), 49-53 (2020)

9. S.V. Fedosov, V.N. Fedoseev, A.B. Petrukhin, I.A. Martynov, L.A. Oparina, Energy efficiency of using a buffer tank in heating mode with heat generators for low-rise textile buildings, Textile and light industry 2, 8-10 (2018)

10. Patent RF 174083. Heat pump, V.N. Fedoseev, V.A. Emelin, V.A. Raven eye. Appl. dated 09.01.2017. Publ. 09/29/2017. Bulletin№ 28.

11. S.V. Fedosov, V.N. Fedoseev, I.A. Zajceva, Recirculated air heat pump with recuperation application experience. Ventilation, heating, air conditioning, heat supply, building thermal physics M.: AVOK-PRESS 8, 54-57 (2020)

12. I. Staffell, D.J.L. Brett, N. Brandon, A. Hawkes, A review of domestic heat pumps, Energy \& Environmental Science 5(11), 9291-9306 (2012)

13. P. Carroll, M. Chesser, P. Lyons, Air Source Heat Pumps field studies: A systematic literature review, Renewable and Sustainable Energy Reviews 134,110275(2020)

14. Package of mathematical software Mathcadv.15.0

15. Operating instructions for a heat pump with heat transfer from air to water https://solardom.com/upload/iblock/287/Meeting_user_manual_MD_RU_.pdf.

16. D. Ray, D. Michael, Heat pumps (Translated from English, Energoizdat, Moscow, 1982)

17. R NP "AVOK" 5.2-2012 "Technical recommendations for the organization of air exchange in apartments in residential buildings." M.: AVOK-PRESS (2012).

18. SanPiN 2.2.4.548-96 "Physical factors of the working environment. Hygienic requirements for the microclimate of industrial premises. Sanitary rules and norms "/ Approved. Resolution of the State Committee for Sanitary and Epidemiological Supervision of the Russian Federation dated 01.10.1996 № 21. M. (1996)

19. Yu.A. Tabunshchikov, M.M. Brodach, Mathematical modeling and optimization of thermal efficiency of buildings (AVOK-PRESS, Moscow, 2002) 